\title{
Change in the stimulus produced by nonreward as a function of time'
}

\section{E. J. CAPALDI AND ROBERT MINKOFF}

UNIVERSITY OF TEXAS

For all rats half the daily acquisition intertrial intervals (ITI) were $8 \mathrm{~min}$., half $30 \mathrm{sec}$. Reward followed nonreward at the $8 \mathrm{~min}$. ITI in one group and at the $30 \mathrm{sec}$. ITI in the other. In extinction, trials occurred at a constant $8 \mathrm{~min}$. ITI for half of each group, and at a constant $30 \mathrm{sec}$. ITI for the remaining half. Only the interaction between the acquisition nonreward-reward ITI and the extinction ITI was significant. These results suggest that the nonrewarded stimulus changes over time but that its response evoking power is neither increased nor decreased by the change.

Both mediating reactions and stimulus traces assume that the stimulus complex on a trial (Tn) is influenced by the reward outcome on the previous trial (Tn-1) or trials (Capaldi, in press). Little has been done to determine how these reward related stimuli may be influenced by intertrial interval (ITI). Refer to reward produced stimuli as $\mathrm{S}^{\mathrm{R}}$ (or $\mathbf{s}_{\mathrm{g}}$ ) and to nonreward produced stimuli as $\mathrm{S}^{\mathrm{N}}$ (or $\mathrm{s}_{\mathrm{ng}}$ ). Assume that these stimuli change systematically over time.. From this it follows that if a given age of, e.g., $\mathrm{S}^{\mathrm{N}}$ is conditioned to the reaction, younger and older ages of $\mathrm{SN}$ will possess only a generalized and therefore a weaker capacity to evoke the reaction. This hypothesis suggested by Capaldi \& Poynor (1966) in an attempt to explain a body of results which deviated slightly from theoretical expectation, was tested here.

Little in the way of previous experimental work or theorizing is particularly relevant to the present issue. Within the trace framework concern has been invested in whether or not $\mathrm{S}^{\mathrm{N}}$ is functional following a long ITI (e.g., Sheffield, 1949; Capaldi \& Stanley, 1963) and within the mediating reaction framework the issue of changes in $\mathbf{s}_{\mathbf{g}}$ or $\mathbf{s}_{\mathrm{ng}}$ over time seems not to have been directly considered. The later position assumes that $\mathrm{s}_{\mathrm{g}}$ is related to $\mathrm{r}_{\mathrm{g}}$. It seems reasonable to suppose that the $r_{g}$ (or the $r_{n g}$ ) evoked on $T n$ is not identical following different ITIs.

Method

The 40 naive male rats about 100 days old were purchased from Harlan Industries, Cumberland, Indiana. The initial portion of the alley was an 8-in. floor treadle which, when depressed by the rat, whose front paws were always placed at its forward edge, started the first clock (.01 sec.). Clock 1 was stopped (start time) and Clock 2 started when S interrupted a photobeam 2 in. beyond the treadle. Clock 2 was stopped (run time) and Clock 3 started when $\mathrm{S}$ broke the second photobeam located 52 in. from the first. The last photobeam was $15-1 / 4$ in. beyond the second photobeam (goal time) and 2-3/4 in. in front of a brass $2 \times 4 \times 1-1 / 2$ in. food cup covered by a sliding lid which opened automatically when the last photobeam was broken. There were two identical food cups, one for reinforced trials (wet mash) and one for nonreinforced trials. A manually-lowered guillotine door, 14 in. from the rear of the goal compartment, served to confine $S$ to the goal area. The apparatus was gray.

Experimental training followed 10 days of deprivation (7-8 $\mathrm{gm})$, two days of handling (11-12), a baited goal box placement (day 13), and four rewarded runway trials (days 14 and 15). The design was a 2 by 2 factorial. In acquisition (five trials per day for six days) all Ss received the same schedule of rewarded $(R)$ and nonrewarded (N) trials each day, i.e., RNRNR. For group N30 the ITI between $N$ and $R$ trials was always 30 sec., the ITI between $R$ and $N$ trials being a minimum of 8 min. (maximum $15 \mathrm{~min}$.). For group N8 conditions were reversed, ITI between $N$ and $R$ trials a minimum of 8 min., ITI between $R$ and $N$ trials always $30 \mathrm{sec}$. Thus both groups received two $30 \mathrm{sec}$. and two $8 \mathrm{~min}$. ITIs daily. However, for $N 30$ the $30 \mathrm{sec}$. age of $\mathrm{S}^{\mathrm{N}}$ was conditioned to the reaction ( $R$ trial) and for $N 8$ the 8 min. age of $\mathrm{S}^{\mathrm{N}}$ was conditioned. Extinction trials (five per day for three days) occurred at a constant ITI of either $30 \mathrm{sec}$. or $8 \mathrm{~min}$. (minimum), half of each acquisition group receiving the $30 \mathrm{sec}$. ITI (N30-N30, N8-N30) half the $8 \mathrm{~min}$. ITI (N30-N8, N8-N8). Following the last day of extinction all ITIs were reversed, e.g., N30-N8-N30. Goal box confinement was 30 sec. on all trials ( $R=$ mash). The Ss were run in squads of five each in rotation. The data of three Ss which died (two from N8-N8, one from N30-N30) were discarded. The Ss were fed the daily ration $10 \mathrm{~min}$. following the last trial of the day.

Resulis

Figure 1 shows for each of the four groups the mean $\log$ times in the run section for each of the three days of extinction and the reversal day. Differences on the last day of acquisition were not significant $(F<1)$. Figure 1 shows that groups which had in extinction the age of $\mathrm{S}^{\mathrm{N}}$ directly conditioned in acquisition (N30-N30, N8-N8) ran faster than groups which had in extinction the age of $\mathrm{S}^{\mathrm{N}}$ not directly conditioned in acquisition, i.e., groups which had the generalized age of $\mathrm{s}^{\mathbf{N}}$ (N30-N8, N8-N30). A 2 by 2 analysis over each day of extinction ( $d f=1 / 32$ in each case) indicated that neither the acquisition main effect ( $F<1,1.34,<1$, respectively) nor the extinction main effect $(F<1,1.03,<1$, respectively) were significant on any day. The interaction, 


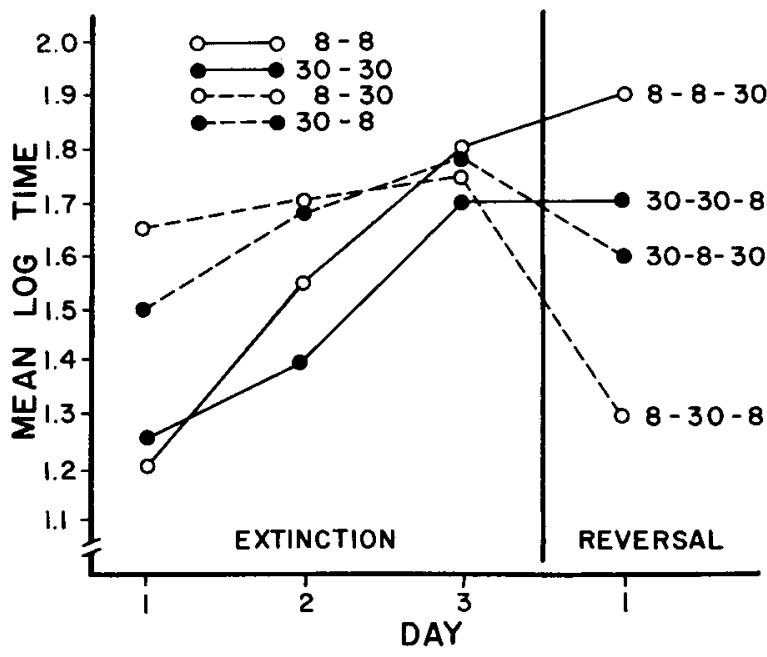

Fig. 1. Mean log times in the run section for each of the four groups on each of the three days of extinction and the reversal day.

however, was highly sigmificant on day 1 of extinction $(\mathrm{F}=16.42, \mathrm{p}<.001)$, substantial on day $2(\mathrm{~F}=11.03$, $\mathrm{p}<.01)$ and nonsignificant by day $3(\mathrm{~F}<1)$. On the reversal day the acquisition main effect was not significant $(F<1)$, the extinction main effect was significant $(F=6.82, p<.05), 8 \mathrm{~min}$. ITI producing faster running than $30 \mathrm{sec}$. ITI, and the interaction was significant $(F=12.26, p<.01)$. The significant interaction in reversal means that $\mathrm{Ss}$ which returned to the age of $\mathrm{S}^{\mathrm{N}}$ conditioned in acquisition (e.g., N30-N8N30) ran faster than Ss which merely had a change in ITI (e.g., N8-N8-N30).

\section{Discussion}

The results suggest that a directly conditioned age of $\mathrm{S}^{\mathrm{N}}$ has greater response evoking power than either a younger or older age of $\mathrm{s}^{\mathrm{N}}$ not directly conditioned. This interaction has a clear meaning; $\mathrm{S}^{\mathrm{N}}$ changes over time. Equally interesting in view of the current state of theorizing is the failure of the acquisition main effect to influence extinction. This failure in combination with the significant interaction suggests that while
$\mathrm{S}^{\mathrm{N}}$ is changing over time, the change has no effect on the capacity of $\mathrm{S}^{\mathrm{N}}$ to evoke reactions. Thus, if as the trace conception suggests $\mathrm{SN}$ dissipates over time, conditioning the $30 \mathrm{sec}$. age of $\mathrm{S}^{\mathrm{N}}$ in acquisition should have produced less extinction than conditioning the $8 \mathrm{~min}$. age of $S^{N}$ in acquisition. It might be argued that $8 \mathrm{~min}$. is not sufficient time for dissipation to occur. It should be remembered, however, that $8 \mathrm{~min}$. was a minimum ITI, that while the data suggest a high degree of discrimination between the $30 \mathrm{sec}$. and $8 \mathrm{~min}$. ages of $\mathrm{S}^{\mathrm{N}}$ they suggest little or no dissipation and that a trace which fails to dissipate even minimally within $8 \mathrm{~min}$. is in danger of losing its status as a trace.

One manner of determining whether or not $\mathrm{S}^{\mathrm{N}}$ is functional at a given ITI is to alternate $\mathrm{R}$ and $\mathrm{N}$ trials; slower running on $N$ than on $R$ trials suggests that $\mathrm{S}^{N}$ is functional at that ITI (Capaldi \& Lynch, 1966). The present reversal results suggest that studies of this type which in effect ask $S$ to run slowly following a long ITI have an inherent weakness which tends to underestimate functionality; longer ITIs are associated with faster running. In some respects then the present investigation which employed both long and short ITIs in extinction provides a more realistic estimate of functionality than other investigations despite its being designed for another purpose.

\section{References}

Capaldi, E. I. A sequential hypothesis of instrumental learning. In K. W. Spence and J. Spence (Eds.), Recent advances in learning and motivation. New York: Academic Press, in press.

Capaldi, E. J., \& Lynch, A. D. Patterning at 24-hr. ITI; resolution of a discrepancy more apparent than real. Psychon. Sci., 1966. 6, 229-230.

Capaldi, E. J., \& Poynor, H. After effects and delay of reward. J. exp. Psychol., 1966, 71, 80-88.

Capaldi, E. J., \& Stanley, L. R. Temporal properties of reinforcement. J. exp. Psychol., 1963, 65, 169-175.

Sheffield, V. F. Extinction as a function of partial reinforcement and distribution of practice. J. exp. Psychol., 1949, 39, 511-526.

\section{Note}

1. This research was supported in part by National Institute of Child Health and Development Research Grant HD 00949-04 to the first author. 